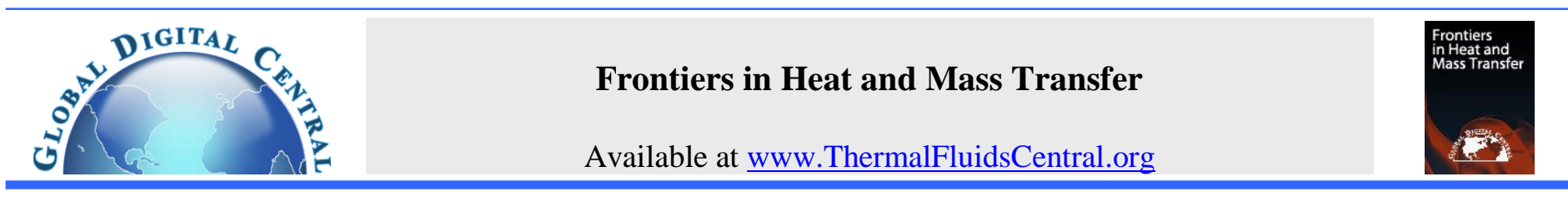

\title{
NUMERICAL SIMULATION OF STEADY FLOW OF VORTEX FLOWMETER
}

\author{
Yan-Juan Zhao, ${ }^{\mathrm{a},}$ Yu-Liang Zhang ${ }^{\mathrm{b}, \dagger}$, Chen-Liang Zhang ${ }^{\mathrm{b}}$ \\ ${ }^{a}$ College of Information Engineering, Quzhou College of Technology, Quzhou, Zhejiang, 324000, China \\ ${ }^{b}$ College of Mechanical Engineering, Quzhou University, Quzhou, Zhejiang, 324000, China
}

\begin{abstract}
Vortex flowmeter adopts advanced micro processing technology, which has the advantages of strong function, wide flow range, simple operation and maintenance, convenient installation and use. It is widely used in petroleum, chemical industry, electric power, metallurgy, urban gas supply and other industries to measure various gas flows. In order to study the characteristics of the inner flow passage of the vortex flowmeter and reach the normal working standard of the vortex flowmeter, this paper uses CFX to calculate the turbulent kinetic energy, eddy viscosity and flow velocity of the inner flow passage of the vortex flowmeter and analyze their distribution, so as to provide a reference for the normal detection and control of the flow of the vortex flowmeter. It is found that the turbulent kinetic energy and eddy viscosity are relatively small, and the flow velocity is distributed evenly in the flow passage of the vortex flowmeter, and the value of the flow velocity in each section of the flow passage has little difference, which is consistent with the stable operation of the vortex flowmeter in each working condition. The application of CFX calculation and simulation technology can improve effectively the rationality of vortex flowmeter design optimization, predict the performance of vortex flowmeter in advance, and improve the efficiency of design optimization.
\end{abstract}

Keywords: vortex flowmeter; Simulation; turbulent kinetic energy; eddy viscosity; flow velocity

\section{INTRODUCTION}

At present, in the process of industrial production, real-time monitoring and control of each medium flow can reduce greatly unnecessary production costs (Zhou, 2019), reduce excessive waste of raw materials, and avoid effectively accidents in the production process. As the most commonly used vortex flowmeter in flow monitoring and control, it also plays an increasingly significant role in the industrial field (Wang, 2019).

Cui Baoling et al.(2015) conducted numerical simulation with RNG K- $\varepsilon$ turbulence model by CFD and combined with experiments to study the $150 \mathrm{~mm}$ diameter precession vortex flowmeter, and pointed out that when the incidence angle of the spinner is $55^{\circ}$, the performance of the precession vortex flowmeter is the best. Yang Youwei et al. (2019) analyzed the errors in the use process and the causes of the errors in the verification process of flowmeter, and put forward the offline verification and verification methods in the offline verification process of oilfield metering, so as to minimize the errors and achieve the purpose of accurate measurement. Arumuru venugopal et al. (2019) detect the low flow velocity through the eddy current frequency generated by the blunt body, and put forward a new design to encapsulate the interference arm in the metal shell to protect the sensor from the influence of bad process fluid. Zhang Ying (2019) used MCM to evaluate the measurement uncertainty of the vortex flowmeter, and found that the precession frequency of the vortex is directly proportional to the flow rate. Tan wenao et al. (2019) used the computational software Fluent of fluid dynamics to carry out numerical simulation and experimental research on gas-solid two-phase flow in the flowmeter. It was found that the larger the particle concentration, the smaller the pressure frequency at the monitoring point, the smaller the reading of the flowmeter, the more complex the fluid flow, and the more the solid particle distribution on the channel wall. He Linhan et al. (2019) made a detailed discussion on the influence of gas composition by analyzing the factors affecting the instrument error. It was found that the lower the content of different gas compositions in natural gas, the greater the relative density of gas, and the larger the flow when converted into standard condition.

Different from the above research, in this paper, CFD (Huang et al., 2019; Kim, et al., 2019; Fan et al., 2019; Zhang and Yao, 2019) is used to analyze and calculate the turbulent kinetic energy, eddy viscosity and flow velocity in the inner flow passage of vortex flowmeter, and then predict the working performance of vortex flowmeter and improve its application efficiency.

\section{CALCULATION SETTING}

\subsection{Physical Model}

The basic parameters of the spinner are selected as shown in Fig. 1.
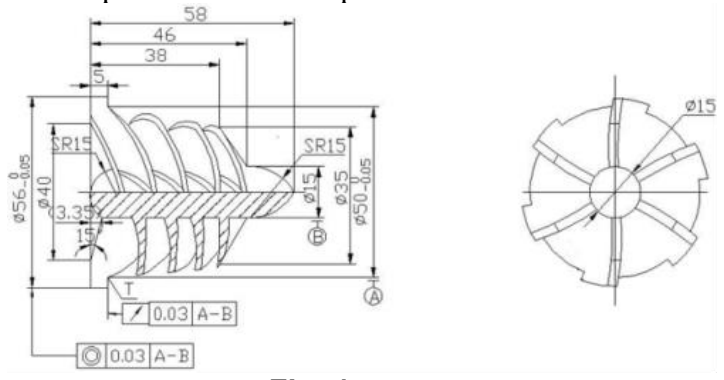

Fig. 1 Spinner

\footnotetext{
* College of Information Engineering, Quzhou College of Technology, Quzhou, Zhejiang, 324000, China

† Corresponding author.Email: zhang002@sina.com
} 


\subsection{Governing Equations}

The three-dimensional incompressible viscous flows in a vortex flowmeter could be described by Reynolds average equation.

$$
\left\{\begin{array}{c}
\frac{\partial \bar{u}_{i}}{\partial x_{i}}=0 \\
\rho \frac{\partial \bar{u}_{i}}{\partial t}+\rho \bar{u}_{j} \frac{\partial \bar{u}_{i}}{\partial x_{j}}=\rho F_{i}-\frac{\partial \bar{p}}{\partial x_{i}}+\mu \frac{\partial^{2} \bar{u}_{i}}{\partial x_{j} \partial x_{j}}-\rho \frac{\partial}{\partial x_{j}}\left(\overline{\bar{u}_{i}^{\prime} u_{j}^{\prime}}\right)
\end{array}\right.
$$

Where $\rho$ is the fluid density, $-\rho \overline{u_{i}^{\prime} u_{j}^{\prime}}$ denotes the average Reynolds stress.

According to Boussinesq hypothesis,

$$
-\rho \overline{u_{i} \bar{u}_{j}^{\prime}}=\mu_{t}\left(\frac{\partial \bar{u}_{i}}{\partial x_{j}}+\frac{\partial \bar{u}_{j}}{\partial x_{i}}\right)-\frac{2}{3}\left(\rho k+\mu_{t} \frac{\partial \bar{u}_{i}}{\partial x_{i}}\right) \delta_{i j}
$$

where $\mu_{t}$ is turbulence viscous coefficient, which is the function of turbulence kinetic energy $\mathrm{k}$ and turbulent dissipation rate $\varepsilon$.

The RNG k- $\varepsilon$ turbulence model is chosen to close the Reynolds averaged Navier-Stokes equations.

Turbulence kinetic energy equation and turbulent dissipation rate equation are following.

$$
\begin{aligned}
& \rho \frac{D k}{D t}=\frac{\partial}{\partial x_{i}}\left[\left(\alpha_{k} \mu_{e f f}\right) \frac{\partial k}{\partial x_{i}}\right]+G_{k}+G_{b}-\rho \varepsilon-Y_{M} \\
& \rho \frac{D \varepsilon}{D t}=\frac{\partial}{\partial x_{i}}\left[\left(\alpha_{\varepsilon} \mu_{e f f}\right) \frac{\partial \varepsilon}{\partial x_{i}}\right]+C_{1 \varepsilon} \frac{\varepsilon}{k}\left(G_{k}+C_{3 \varepsilon} G_{b}\right)-C_{2 \varepsilon} \rho \frac{\varepsilon^{2}}{k}-R
\end{aligned}
$$

\subsection{Grid Division}

After 3D digital modeling of vortex flowmeter with UG, the model file is imported into ICEM CFD in step format, and the whole model is partitioned and a new part is created at the same time. The grid type is selected and the model is meshed, mainly hexahedral grid. The grid dependency study is carried out for present model, it is found that the pressure loss correlation is less than $1 \%$ and there is almost no difference among the flow fields. Consequently, the influence of the grid numbers on the numerical results can be ignored. The final grid number used in the computation is 790000 grids. The value of $y+$ is taken as about 30 near the boundary wall. The grid number is able to correctly predict the external performance and capture the macroscopical basic flow phenomenon. The spinner grid is shown in Fig. 2 (a), the racer grid is shown in Fig. 2 (b), and the overall calculation domain grid is shown in Fig. 2 (c).

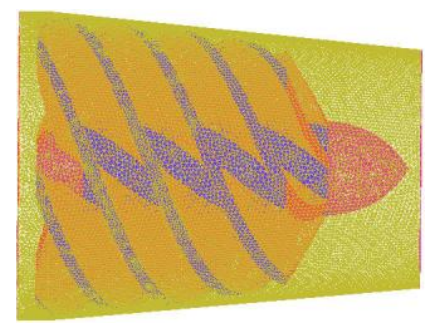

(a) Spinner grid

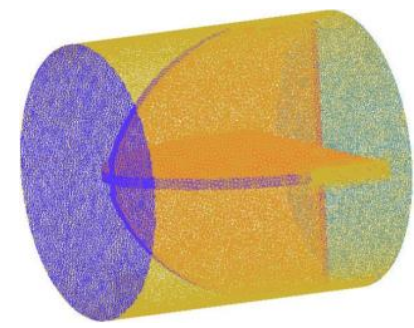

(b) Racer grid

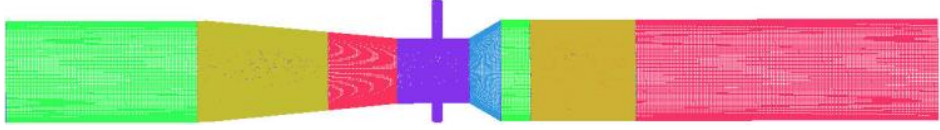

(c) Overall grid

Fig. 2 Computational domain grid

\subsection{Boundary conditions}

Velocity inlet is selected as inlet boundary condition. Assume that inlet velocity is uniform at axis direction and its value equals to the ratio of flow rate and inlet area. Outflow is specified as the outlet boundary condition. As to wall boundary condition, no slip condition is enforced on wall surface and standard wall function is also applied to adjacent region of the walls. The first order upwind scheme with numerical under-relaxation is applied for the discretization of the convection term and the central difference scheme is employed for the diffusion term. The pressure-velocity coupling is solved through the SIMPLE algorithm. Convergence precision of all residuals is under 0.0001. In author previous works, the numerical method has been verified that it is able to accurately calculate the flowmeter performance by comparing with the experimental data (Zhang, et al., 2019).

\section{RESULT ANALYSIS}

\subsection{Turbulent Kinetic Energy Distribution}

The turbulent kinetic energy distribution of vortex flowmeter is analyzed under the conditions of $10 \mathrm{~m}^{3} / \mathrm{h}, 30 \mathrm{~m}^{3} / \mathrm{h}, 60 \mathrm{~m}^{3} / \mathrm{h}$ and $90 \mathrm{~m}^{3} / \mathrm{h}$ respectively.

(1) Horizontal middle section

Fig. 3 (a) shows that when the inlet flow rate is $10 \mathrm{~m} 3 / \mathrm{h}$, the turbulent kinetic energy of each part of the flow channel in the vortex flowmeter have little difference. Fig. 3 (b) shows that when the inlet flow rate is $30 \mathrm{~m} 3 / \mathrm{h}$, the highest turbulent kinetic energy appears on both sides of the expansion section, with a value of $63 \mathrm{~m}^{2} / \mathrm{s}^{2}$, and the turbulent kinetic energy of the other parts are low and have little changed, and the value is $10 \mathrm{~m}^{2} / \mathrm{s}^{2}$. Fig. 3 (c) shows that when the inlet flow is $60 \mathrm{~m}^{3} / \mathrm{h}$, the highest turbulent kinetic energy appears on both sides of the expansion section, with a value of $126 \mathrm{~m}^{2} / \mathrm{s}^{2}$. The turbulent kinetic energy in other parts are low and have little change, with a value of $21 \mathrm{~m}^{2} / \mathrm{s}^{2}$. Fig. 3 (d) shows that when the inlet flow is $90 \mathrm{~m}^{3} / \mathrm{h}$, the highest turbulent kinetic energy appears on both sides of the expansion section, with a value of $379 \mathrm{~m}^{2} / \mathrm{s}^{2}$. The lowest turbulent kinetic energy appears at the inlet, with a turbulent kinetic energy of $42 \mathrm{~m}^{2} / \mathrm{s}^{2}$.

It can be seen that after the gas enters into the contraction section, the vortex is formed at the top of the spinner under the influence of the spinner. At any inlet flow rate, a lower turbulent kinetic energy area will be formed on both sides of the spinner, the turbulent kinetic energy on both sides is higher than that in the middle, and a higher turbulent kinetic energy area will be formed on both sides of the expansion section. The larger the inlet flow is, the higher the value of the turbulent kinetic energy area is.
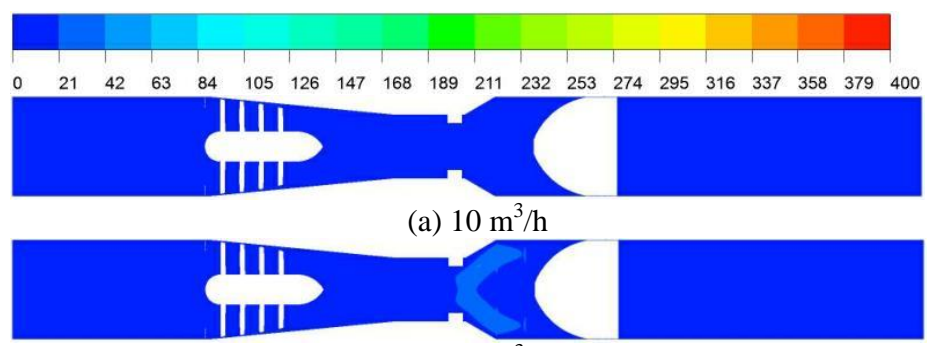

(b) $30 \mathrm{~m}^{3} / \mathrm{h}$

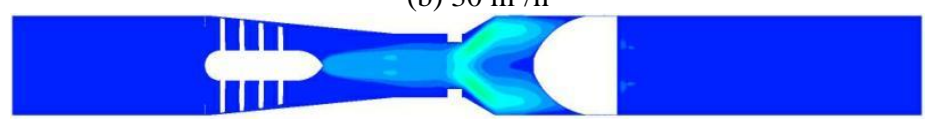

(c) $60 \mathrm{~m}^{3} / \mathrm{h}$
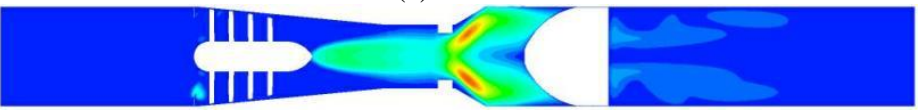

(d) $90 \mathrm{~m}^{3} / \mathrm{h}$

Fig. 3 Turbulent kinetic energy distribution in horizontal middle section $\left(\mathrm{m}^{2} / \mathrm{s}^{2}\right)$

(2) Vertical middle section

Fig. 4 (a) shows that when the inlet flow rate is $10 \mathrm{~m}^{3} / \mathrm{h}$, the turbulent kinetic energy values of each part of the flow channel in the vortex flowmeter have little difference. Fig. 4 (b) shows that when the inlet flow rate is $30 \mathrm{~m}^{3} / \mathrm{h}$, the highest turbulent kinetic energy appears on both sides of the expansion section, with a value of $57 \mathrm{~m}^{2} / \mathrm{s}^{2}$, and the turbulent kinetic energy of the other parts are low and little changed, 
with a value of $10 \mathrm{~m}^{2} / \mathrm{s}^{2}$. Fig.4 (c) shows that when the inlet flow rate is $60 \mathrm{~m}^{3} / \mathrm{h}$, the highest turbulent kinetic energy appears on both sides of the expansion section, with a value of $114 \mathrm{~m}^{2} / \mathrm{s}^{2}$. The turbulent kinetic energy in other parts are low and have little change, with a value of 21 $\mathrm{m}^{2} / \mathrm{s}^{2}$. Fig. 4 (d) shows that when the inlet flow is $90 \mathrm{~m}^{3} / \mathrm{h}$, the highest turbulent kinetic energy appears on both sides of the expansion section, with a value of $360 \mathrm{~m}^{2} / \mathrm{s}^{2}$, and the lowest turbulent kinetic energy appears at the inlet, with a value of $42 \mathrm{~m}^{2} / \mathrm{s}^{2}$.

It can be seen that after the gas enters into the contraction section, the vortex is formed at the top of the spinner under the influence of the spinner. At any inlet flow rate, a lower turbulent kinetic energy area will be formed on both sides of the spinner, the turbulent kinetic energy on both sides is higher than that in the middle, and a higher turbulent kinetic energy area will be formed on both sides of the expansion section. The larger the inlet flow is, the higher the value of the turbulent kinetic energy area is.

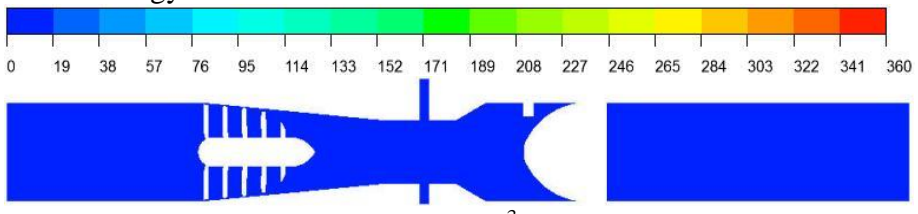

(a) $10 \mathrm{~m}^{3} / \mathrm{h}$

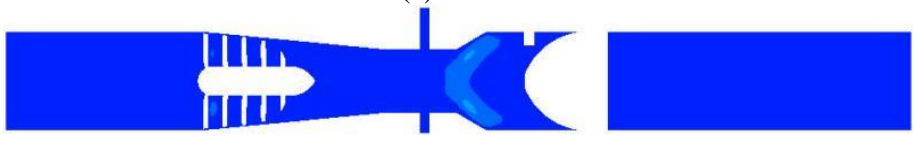

(b) $30 \mathrm{~m} 3 / \mathrm{h}$
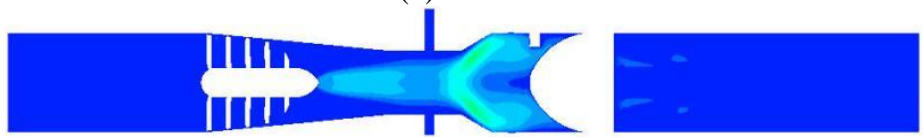

(c) $60 \mathrm{~m} 3 / \mathrm{h}$
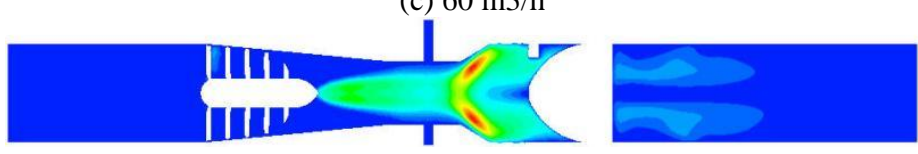

(d) $90 \mathrm{~m} 3 / \mathrm{h}$

Fig. 4 Turbulent kinetic energy distribution in vertical middle section $\left(\mathrm{m}^{2} / \mathrm{s}^{2}\right)$

(3) Pressure sensing cross section

Fig. 5 (a) shows that when the inlet flow rate is $10 \mathrm{~m}^{3} / \mathrm{h}$, the turbulent kinetic energy values of each part of the flow channel in the vortex flowmeter have little difference, and the value is $6 \mathrm{~m}^{2} / \mathrm{s}^{2}$. Fig. 5 (b) shows that when the inlet flow is $30 \mathrm{~m}^{3} / \mathrm{h}$, the lowest turbulent kinetic energy appears on the wall of the flow passage, with a value of 6 $\mathrm{m}^{2} / \mathrm{s}^{2}$. The turbulent kinetic energy at the center is higher, with a value of $44 \mathrm{~m}^{2} / \mathrm{s}^{2}$. Fig. 5 (c) shows that when the inlet flow is $60 \mathrm{~m}^{3} / \mathrm{h}$, the lowest turbulent kinetic energy appears on the wall of the flow passage, with a value of $6 \mathrm{~m}^{2} / \mathrm{s}^{2}$. The turbulent kinetic energy at the center is higher, with a value of $51 \mathrm{~m}^{2} / \mathrm{s}^{2}$. Fig. 5 (d) shows that when the inlet flow is $90 \mathrm{~m}^{3} / \mathrm{h}$, the lowest turbulent kinetic energy appears on the wall of the flow passage, with a value of $38 \mathrm{~m}^{2} / \mathrm{s}^{2}$. The highest turbulent kinetic energy appears at the center, with a value of $120 \mathrm{~m}^{2} / \mathrm{s}^{2}$.

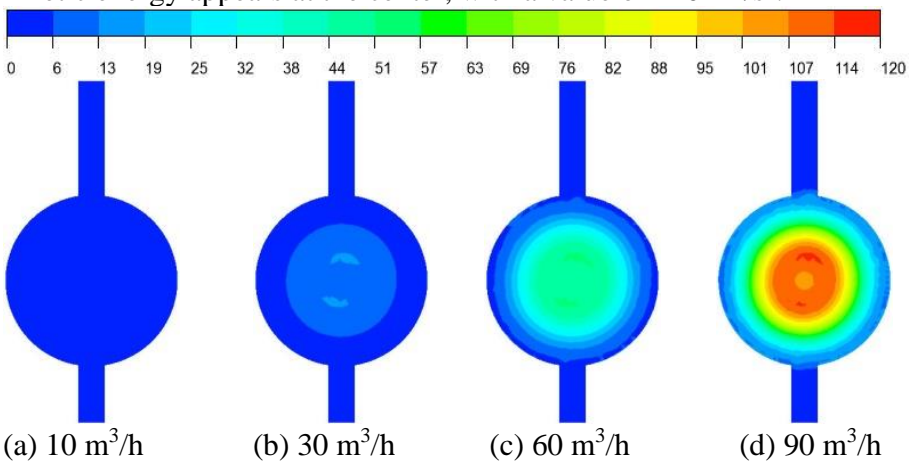

Fig.5 Turbulent kinetic energy distribution in pressure sensing cross section $\left(\mathrm{m}^{2} / \mathrm{s}^{2}\right)$
It can be seen that after the gas enters the throat through the spinner, the air flow is affected by the spinner and the vortex is formed at the top of the spinner, the vortex core moves near the center of the cross section. At any inlet flow condition, the turbulent kinetic energy of center part of the flow channel in the vortex flowmeter is higher than that of the wall surface at the cross section, and the center of the turbulent kinetic energy is highest and gradually decreases outward along the diameter direction. The turbulent kinetic energy in the section increases with the increase of the inlet flow rate, the turbulent kinetic energy near the wall of the flow channel rises slowly, and the turbulent kinetic energy at the center changes significantly.

(4) Exit extension cross section

Fig. 6 (a) shows that when the inlet flow rate is $10 \mathrm{~m}^{3} / \mathrm{h}$, the turbulent kinetic energy values of each part of the flow channel in the vortex flowmeter have little difference, and the value is $2 \mathrm{~m}^{2} / \mathrm{s}^{2}$. Fig. 6 (b) shows that when the inlet flow rate is $30 \mathrm{~m}^{3} / \mathrm{h}$, the lowest turbulent kinetic energy appears at the wall surface of the flow channel, and its value is $2 \mathrm{~m}^{2} / \mathrm{s}^{2}$, the turbulent kinetic energy at the center is low and does not change much, and its value is $35 \mathrm{~m}^{2} / \mathrm{s}^{2}$, four high turbulent kinetic energy areas appear around the center, the value is $8 \mathrm{~m}^{2} / \mathrm{s}^{2}$. Fig. 6 (c) shows that when the inlet flow rate is $60 \mathrm{~m}^{3} / \mathrm{h}$, the lowest turbulent kinetic energy appears at the wall surface of the flow channel, and its value is $2 \mathrm{~m}^{2} / \mathrm{s}^{2}$, the value of turbulent kinetic energy at the center is low and does not change much, and its value is $8 \mathrm{~m}^{2} / \mathrm{s}^{2}$, four high turbulent kinetic energy areas appear around the center, with a value of $-12 \mathrm{~m}^{2} / \mathrm{s}^{2}$. Fig. 6 (d) shows that when the inlet flow rate is $90 \mathrm{~m}^{3} / \mathrm{h}$, the lowest turbulent kinetic energy appears at the wall surface of the flow channel, and its value is $6 \mathrm{~m}^{2} / \mathrm{s}^{2}$, the highest turbulent kinetic energy appears around the center, with a value of $36 \mathrm{~m}^{2} / \mathrm{s}^{2}$.

It can be seen that after the gas enters the throat through the spinner, the air flow is affected by the spinner and the vortex is formed at the top of the spinner, the vortex core moves near the center of the cross section. At any inlet flow conditions, the turbulent kinetic energy of center of the vortex flowmeter outlet at the cross section is higher than that of the wall, four high turbulent kinetic energy areas are formed around the center and gradually decrease outward along the diameter direction. The turbulent kinetic energy in the section increases with the increase of the inlet flow rate, the total pressure near the wall of the flow channel rises slowly, and the turbulent kinetic energy in the four high turbulent kinetic energy areas in the center changes greatly and remains at a high value.

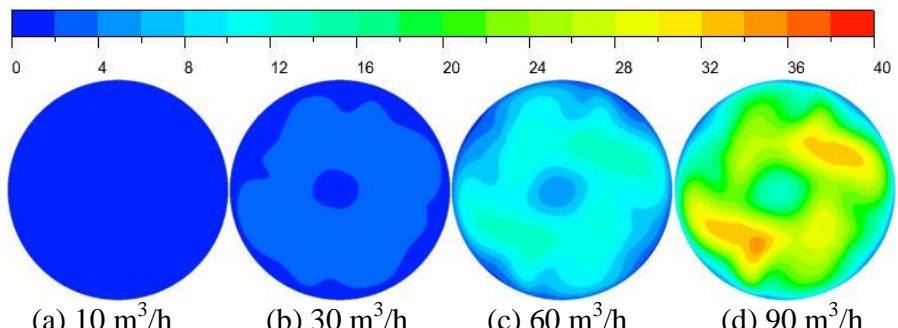

Fig.6 Turbulent kinetic energy distribution in exit extension cross section $\left(\mathrm{m}^{2} / \mathrm{s}^{2}\right)$

\section{(5) Top cross section of spinner}

Fig. 7 (a) shows that when the inlet flow rate is $10 \mathrm{~m}^{3} / \mathrm{h}$, the turbulent kinetic energy values of each part of the flow channel in the vortex flowmeter have little difference, and the value is $6 \mathrm{~m}^{2} / \mathrm{s}^{2}$. Fig. 7 (b) shows that when the inlet flow rate is $30 \mathrm{~m}^{3} / \mathrm{h}$, the turbulent kinetic energy values of each part of the flow channel in the vortex flowmeter have little difference, and the value is $8 \mathrm{~m}^{2} / \mathrm{s}^{2}$. Fig. 7 (c) shows that when the inlet flow is $60 \mathrm{~m}^{3} / \mathrm{h}$, the lowest turbulent kinetic energy appears on the wall of the flow passage, with a value of $6 \mathrm{~m}^{2} / \mathrm{s}^{2}$. The value of turbulent kinetic energy at the center is higher, with a value of $8 \mathrm{~m}^{2} / \mathrm{s}^{2}$. Fig. 7 (d) shows that when the inlet flow is $90 \mathrm{~m}^{3} / \mathrm{h}$, the lowest turbulent kinetic energy appears on the wall of the flow passage, with a value of $6 \mathrm{~m}^{2} / \mathrm{s}^{2}$. The highest turbulent kinetic energy appears at the center, with a value of $120 \mathrm{~m}^{2} / \mathrm{s}^{2}$. 
It can be seen that after the gas enters the throat through the spinner, the air flow is affected by the spinner and the vortex is formed at the top of the spinner, the vortex core moves near the center of the cross section. At any inlet flow condition, the turbulent kinetic energy of center part of the flow channel in the vortex flowmeter is higher than that of the wall surface at the cross section, and the center of the turbulent kinetic energy is highest and gradually decreases outward along the diameter direction. The inlet flow of $10 \mathrm{~m}^{3} / \mathrm{h}$ and the inlet flow of $30 \mathrm{~m}^{3} / \mathrm{h}$ have no significant effect on the turbulent kinetic energy changes in the flow channel, the turbulent kinetic energy in the section increases with the increase of the inlet flow rate, the turbulent kinetic energy near the wall of the flow channel rises slowly, and the turbulent kinetic energy at the center changes significantly.

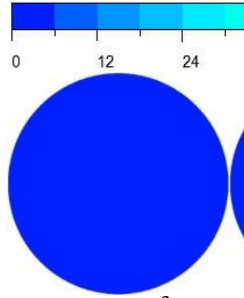

(a) $10 \mathrm{~m}^{3} / \mathrm{h}$

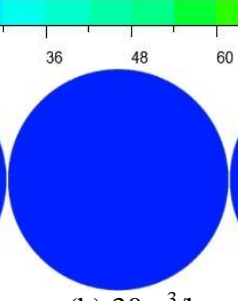

(b) $30 \mathrm{~m}^{3} / \mathrm{h}$

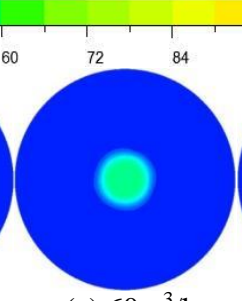

(c) $60 \mathrm{~m}^{3} / \mathrm{h}$

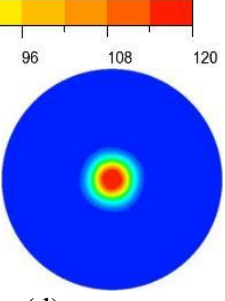

(d)
$90 \mathrm{~m}^{3} / \mathrm{h}$

Fig.7 Turbulent kinetic energy distribution on the top cross section of the spinner $\left(\mathrm{m}^{2} / \mathrm{s}^{2}\right)$

\subsection{Eddy Viscosity Distribution}

The vortex viscosity distribution of the vortex flowmeter was analyzed under the inlet flow of $10 \mathrm{~m}^{3} / \mathrm{h}, 30 \mathrm{~m}^{3} / \mathrm{h}, 60 \mathrm{~m}^{3} / \mathrm{h}$ and $90 \mathrm{~m}^{3} / \mathrm{h}$, respectively.

(1) Horizontal middle section

Fig. 8 (a) shows that when the inlet flow rate is $10 \mathrm{~m}^{3} / \mathrm{h}$, the vortex viscosity on both sides of the expansion section of the vortex flowmeter is the highest, with a value of $6 \mathrm{~Pa} \cdot \mathrm{s}$. The other parts of the vortex viscosity have little difference, with a value of $2 \mathrm{~Pa} \cdot \mathrm{s}$.
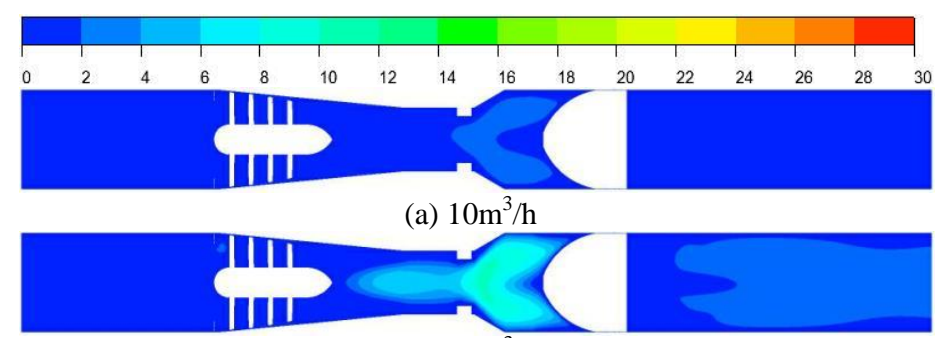

(b) $30 \mathrm{~m}^{3} / \mathrm{h}$
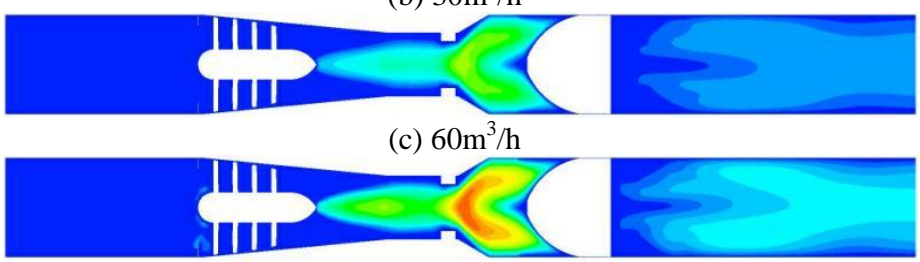

(d) $90 \mathrm{~m}^{3} / \mathrm{h}$

Fig.8 Eddy viscosity distribution in horizontal middle section $(\mathrm{Pa} \cdot \mathrm{s})$

Fig. 8 (b) shows that when the inlet flow is $30 \mathrm{~m}^{3} / \mathrm{h}$, the highest eddy viscosity appears on both sides of the expansion section and the middle of the throat, with a value of $10 \mathrm{~Pa} \cdot \mathrm{s}$, and the eddy viscosity of the outlet extension section also increases, with a value of $6 \mathrm{~Pa} \cdot \mathrm{s}$. Fig. 8 (c) shows that when the inlet flow is $60 \mathrm{~m}^{3} / \mathrm{h}$, the highest eddy viscosity appears on both sides of the expansion section, with a value of $16 \mathrm{~Pa} \cdot \mathrm{s}$, and there are also multiple increases in eddy viscosity at the outlet extension section, with a value of $8 \mathrm{~Pa} \cdot \mathrm{s}$. Fig. 8 (d) shows that when the inlet flow is $90 \mathrm{~m}^{3} / \mathrm{h}$, the highest eddy viscosity appears on both sides of the expansion section and the middle of the outlet section at the throat, with a value of $28 \mathrm{~Pa} \cdot \mathrm{s}$, the lowest eddy viscosity appears at the inlet, and its value is $2 \mathrm{~Pa} \cdot \mathrm{s}$.

It can be seen that after the gas enters into the contraction section, the vortex is formed at the top of the spinner under the influence of the spinner. Under any condition of inlet flow, a high eddy viscosity area will be formed on both sides of the expansion section, and the eddy viscosity on both sides of the throat is lower than that in the middle. The larger the inlet flow is, the higher the value of the eddy viscosity area is.

(2) Vertical middle section

Fig. 9 (a) shows that when the inlet flow rate is $10 \mathrm{~m}^{3} / \mathrm{h}$, the eddy viscosity on both sides of the expansion section of the vortex flowmeter is the highest, with a value of $6 \mathrm{~Pa} \cdot \mathrm{s}$, and the eddy viscosity values of other parts are similar, with a value of 2 Pa.s. Fig. 9 (b) shows that when the inlet flow rate is $30 \mathrm{~m}^{3} / \mathrm{h}$, the highest eddy viscosity appears on both sides of the expansion section and the middle of the throat, with a value of $10 \mathrm{~Pa} \cdot \mathrm{s}$, and the eddy viscosity of the outlet extension section also increases, its value is $6 \mathrm{~Pa} \cdot \mathrm{s}$. Fig. 9 (c) shows that when the inlet flow is $60 \mathrm{~m}^{3} / \mathrm{h}$, the highest eddy viscosity appears on both sides of the expansion section, with a value of $16 \mathrm{~Pa} \cdot \mathrm{s}$, and there are also several increases in eddy viscosity at the outlet extension section, with a value of $8 \mathrm{~Pa} \cdot \mathrm{s}$. Fig. 9 (d) shows that when the inlet flow is $90 \mathrm{~m}^{3} / \mathrm{h}$, the highest eddy viscosity appears on both sides of the expansion section and the middle of the throat outlet section, with a value of $28 \mathrm{~Pa} \cdot \mathrm{s}$, the lowest eddy viscosity appears at the inlet, and its value is $2 \mathrm{~Pa} \cdot \mathrm{s}$.

It can be seen that after the gas enters into the contraction section, the vortex is formed at the top of the spinner under the influence of the spinner. Under any condition of inlet flow, a high eddy viscosity area will be formed on both sides of the expansion section, and the eddy viscosity on both sides of the throat is lower than that in the middle. The larger the inlet flow is, the higher the value of the eddy viscosity area is.

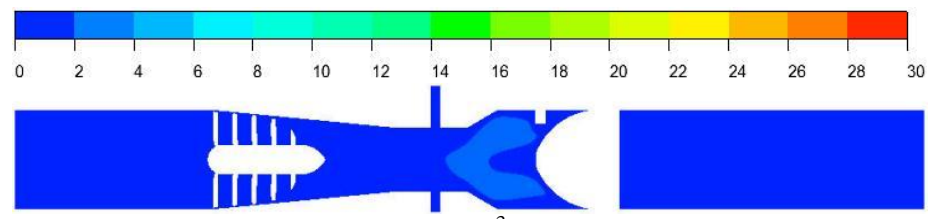

(a) $10 \mathrm{~m}^{3} / \mathrm{h}$
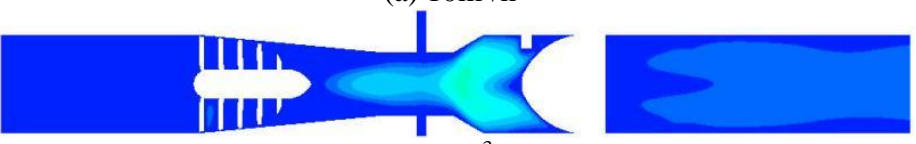

(b) $30 \mathrm{~m}^{3} / \mathrm{h}$
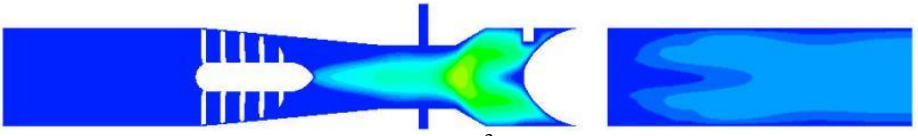

(c) $60 \mathrm{~m}^{3} / \mathrm{h}$
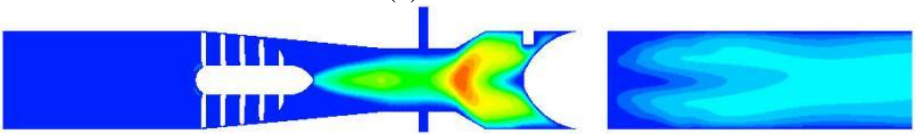

(d) $90 \mathrm{~m}^{3} / \mathrm{h}$

Fig.9 Eddy viscosity distribution of vertical middle section $(\mathrm{Pa} \cdot \mathrm{s})$

(3) Pressure sensing cross section

Fig. 10 (a) shows that when the inlet flow rate is $10 \mathrm{~m}^{3} / \mathrm{h}$, the eddy viscosity value of each part of the cross section of the vortex flowmeter has little difference, and the value is $4 \mathrm{~Pa} \cdot \mathrm{s}$. Fig. 10 (b) shows that when the inlet flow rate is $30 \mathrm{~m}^{3} / \mathrm{h}$, the lowest eddy viscosity appears on the wall of the flow channel, its value is $2 \mathrm{~Pa} \cdot \mathrm{s}$, and the eddy viscosity value of the central part is higher, and the value is $6 \mathrm{~Pa} \cdot \mathrm{s}$. Fig. 10 (c) shows that when the inlet flow is $60 \mathrm{~m}^{3} / \mathrm{h}$, the lowest eddy viscosity appears on the wall of the flow passage, with a value of $2 \mathrm{~Pa} \cdot \mathrm{s}$, and the eddy viscosity values in the center are all high, with a value of $12 \mathrm{~Pa} \cdot \mathrm{s}$. Fig. 10 (d) shows that when the inlet flow is $90 \mathrm{~m}^{3} / \mathrm{h}$, the lowest eddy viscosity appears on the wall of the flow passage, with a value of $2 \mathrm{~Pa} \cdot \mathrm{s}$, 
and the highest eddy viscosity appears in the center, with a value of 16 $\mathrm{Pa} \cdot \mathrm{s}$.

It can be seen that after the gas enters the throat through the spinner, the air flow is affected by the spinner and the vortex is formed at the top of the spinner, and the vortex core of the vortex moves near the center of the cross section. Under any condition of inlet flow, the eddy viscosity in the flow passage of center of the vortex flowmeter is higher than that of the wall, and the highest value of the center of eddy viscosity decreases gradually outward along the diameter direction. The eddy viscosity in the cross section increases with the increase of the inlet flow rate. The eddy viscosity near the channel wall rises slowly, and the eddy viscosity at the center changes significantly.

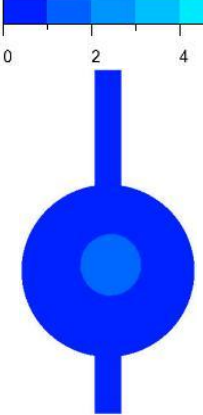

(a) $10 \mathrm{~m}^{3} / \mathrm{h}$

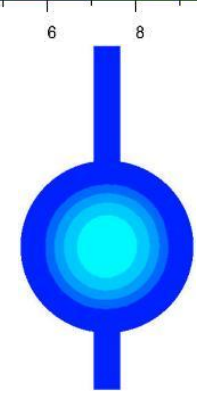

(b) $30 \mathrm{~m}^{3} / \mathrm{h}$

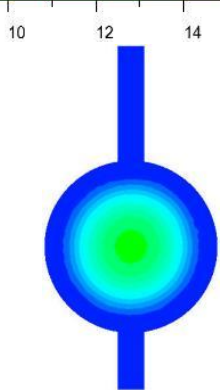

(c) $60 \mathrm{~m}^{3} / \mathrm{h}$

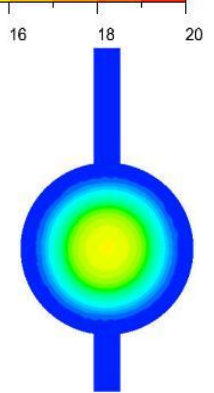

(d) $90 \mathrm{~m}^{3} / \mathrm{h}$
Fig. 10 Eddy viscosity distribution of Pressure sensing cross section $(\mathrm{Pa} \cdot \mathrm{s})$

(4) Exit extension cross section

Fig. 11 (a) shows that when the inlet flow rate is $10 \mathrm{~m}^{3} / \mathrm{h}$, the eddy viscosity of each part of the cross section of the vortex flowmeter has little difference, and its value is $1 \mathrm{~Pa} \cdot \mathrm{s}$. Fig. 11 (b) shows that when the inlet flow rate is $30 \mathrm{~m}^{3} / \mathrm{h}$, the lowest eddy viscosity appears on the wall of the flow passage, with a value of $1 \mathrm{~Pa} \cdot \mathrm{s}$. The eddy viscosity value at the center is low and has little change, with a value of $2 \mathrm{~Pa} \cdot \mathrm{s}$. There are four high eddy viscosity areas around the center, with a value of $3 \mathrm{~Pa} \cdot \mathrm{s}$. Fig. 11 (c) shows that when the inlet flow rate is $60 \mathrm{~m}^{3} / \mathrm{h}$, the lowest eddy viscosity appears on the wall of the flow passage, with a value of $1 \mathrm{~Pa} \cdot \mathrm{s}$. The eddy viscosity value at the center is low and has little change, with a value of $3 \mathrm{~Pa} \cdot \mathrm{s}$. There are four high eddy viscosity areas around the center, with a value of $5 \mathrm{~Pa} \cdot \mathrm{s}$. Fig. 11 (d) shows that when the inlet flow rate is $90 \mathrm{~m}^{3} / \mathrm{h}$, the lowest eddy viscosity appears on the wall of the flow passage, with a value of $1 \mathrm{~Pa} \cdot \mathrm{s}$, and the highest eddy viscosity appears around the center, with a value of $8 \mathrm{~Pa} \cdot \mathrm{s}$.

It can be seen that after the gas enters the throat through the spinner, the air flow is affected by the spinner and the vortex is formed at the top of the spinner, and the vortex core of the vortex moves near the center of the cross section. Under the condition of any inlet flow rate, the eddy viscosity at the outlet of the vortex flowmeter at the center of cross section is higher than that of the wall, and four high eddy viscosity areas are formed around the center and decrease gradually outward along the diameter direction. The eddy viscosity in the cross section increases with the increase of the inlet flow, and the eddy viscosity near the channel wall rises slowly. The eddy viscosity in the center of the four high eddy viscosity areas changes greatly and remains at a high value.

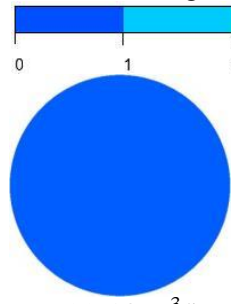

(a) $10 \mathrm{~m}^{3} / \mathrm{h}$

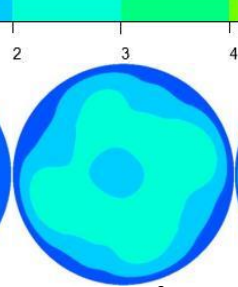

(b) $30 \mathrm{~m}^{3} / \mathrm{h}$

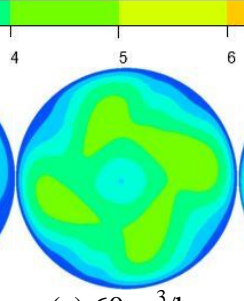

(c) $60 \mathrm{~m}^{3} / \mathrm{h}$

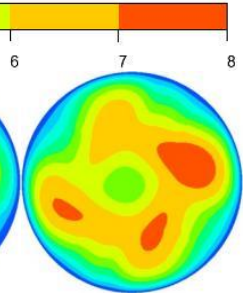

(d) $90 \mathrm{~m}^{3} / \mathrm{h}$
Fig. 11 Eddy viscosity distribution of cross section of outlet extension $(\mathrm{Pa} \cdot \mathrm{s})$

\section{(5) Top cross section of spinner}

Fig. 12 (a) shows that when the inlet flow rate is $10 \mathrm{~m}^{3} / \mathrm{h}$, the eddy viscosity value of each part of the cross section of the vortex flowmeter has little difference, and its value is $1 \mathrm{~Pa} \cdot \mathrm{s}$. Fig. 12 (b) shows that when the inlet flow rate is $30 \mathrm{~m}^{3} / \mathrm{h}$, the lowest eddy viscosity appears on the wall of the flow channel, with a value of $1 \mathrm{~Pa} \cdot \mathrm{s}$, and the eddy viscosity value of the central part is higher, with a value of $3 \mathrm{~Pa}$.s. Fig. 12 (c) shows that when the inlet flow is $60 \mathrm{~m}^{3} / \mathrm{h}$, the lowest eddy viscosity appears on the wall of the flow passage, with a value of $1 \mathrm{~Pa} \cdot \mathrm{s}$, and the central part has a higher value of eddy viscosity, with a value of $5 \mathrm{~Pa} \cdot \mathrm{s}$. Fig. 12 (d) shows that when the inlet flow rate is $90 \mathrm{~m}^{3} / \mathrm{h}$, the lowest eddy viscosity appears on the wall of the flow passage, with a value of $1 \mathrm{~Pa} \cdot \mathrm{s}$, and the highest eddy viscosity appears in the center, with a value of $10 \mathrm{~Pa} \cdot \mathrm{s}$.

It can be seen that after the gas enters the throat through the spinner, the air flow is affected by the spinner and the vortex is formed at the top of the spinner, and the vortex core of the vortex moves near the center of the cross section. Under any condition of inlet flow, the center of eddy viscosity in the flow passage of the vortex flowmeter is higher than that of the wall, and the highest value of the center of eddy viscosity decreases gradually outward along the diameter direction. The eddy viscosity in the cross section increases with the increase of the inlet flow rate. The eddy viscosity near the channel wall rises slowly, and the eddy viscosity at the center changes significantly.

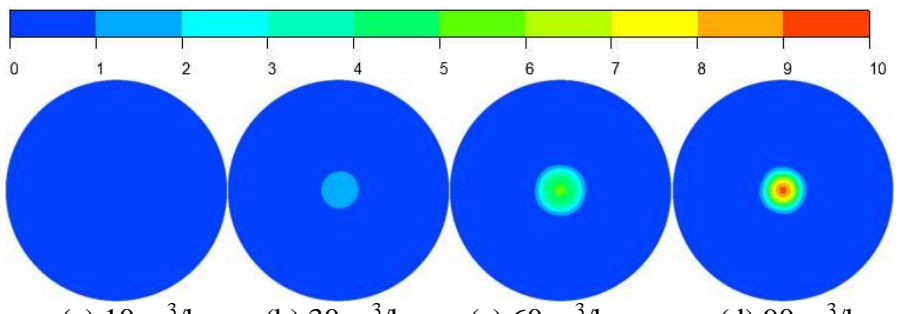
(a) $10 \mathrm{~m}^{3} / \mathrm{h}$
(b) $30 \mathrm{~m}^{3} / \mathrm{h}$
(c) $60 \mathrm{~m}^{3} / \mathrm{h}$
(d) $90 \mathrm{~m}^{3} / \mathrm{h}$

Fig. 12 Eddy viscosity distribution of the top cross section of the

\subsection{Velocity Distribution} spinner $(\mathrm{Pa} \cdot \mathrm{s})$

The velocity distribution of vortex flowmeter is analyzed under the conditions of $10 \mathrm{~m}^{3} / \mathrm{h}, 30 \mathrm{~m}^{3} / \mathrm{h}, 60 \mathrm{~m}^{3} / \mathrm{h}$ and $90 \mathrm{~m}^{3} / \mathrm{h}$ respectively.

\section{(1) Horizontal middle section}

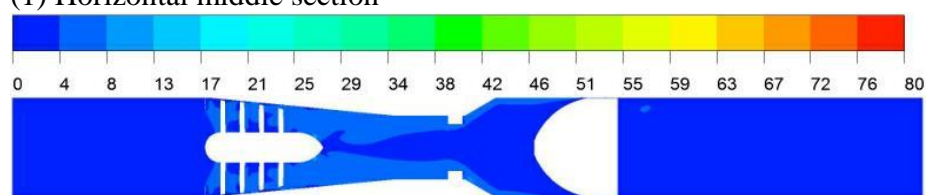

(a) $10 \mathrm{~m}^{3} / \mathrm{h}$

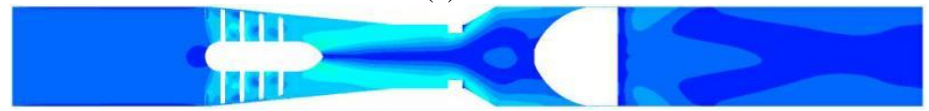

(b) $30 \mathrm{~m}^{3} / \mathrm{h}$

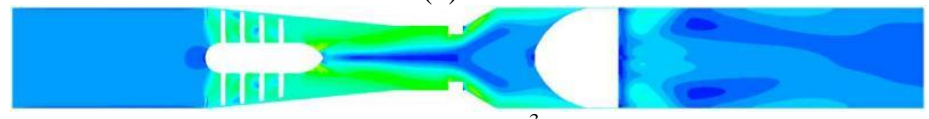

(c) $60 \mathrm{~m}^{3} / \mathrm{h}$
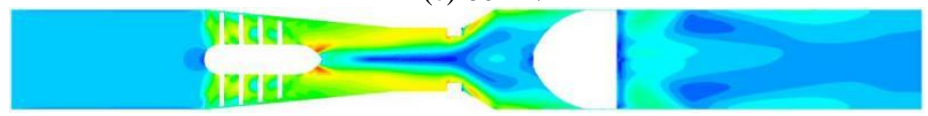

(d) $90 \mathrm{~m}^{3} / \mathrm{h}$

Fig. 13 Velocity distribution of horizontal middle section $(\mathrm{m} / \mathrm{s})$

Fig. 13 (a) shows that when the inlet flow is $10 \mathrm{~m}^{3} / \mathrm{h}$, the lowest velocity appears at the top of the spinner, its value is $4 \mathrm{~m} / \mathrm{s}$, and the highest velocity appears at both sides of the throat of the spinner, its value is $17 \mathrm{~m} / \mathrm{s}$. Fig. 13 (b) shows that when the inlet flow is $30 \mathrm{~m}^{3} / \mathrm{h}$, the lowest velocity appears at the top of the spinner, with a value of 2 $\mathrm{m} / \mathrm{s}$, and the highest velocity appears at both sides of the throat of the spinner, with a value of $21 \mathrm{~m} / \mathrm{s}$. Fig. 13 (c) shows that when the inlet 
flow is $90 \mathrm{~m}^{3} / \mathrm{h}$, the lowest velocity appears on the top of the spinner, with a value of $2 \mathrm{~m} / \mathrm{s}$ and the highest velocity appears on both sides of the throat, with a value of $42 \mathrm{~m} / \mathrm{s}$. Fig. 13 (d) shows that when the inlet flow is $90 \mathrm{~m}^{3} / \mathrm{h}$, the lowest velocity appears on the top of the spinner, with a value of $2 \mathrm{~m} / \mathrm{s}$ and the highest velocity appears on both sides of the throat, with a value of $63 \mathrm{~m} / \mathrm{s}$.

It can be seen that after the gas enters into the contraction section, the vortex is formed at the top of the spinner under the influence of the spinner. Under any condition of inlet flow, a lower velocity area will be formed at the top of the spinner, and the velocity at both sides of the throat is higher than that in the middle.

(2) Vertical middle section

Fig. 14 (a) shows that when the inlet flow is $10 \mathrm{~m}^{3} / \mathrm{h}$, the lowest velocity appears at the top of the spinner, with a value of $6 \mathrm{~m} / \mathrm{s}$, and the highest velocity appears at both sides of the throat, with a value of 18 $\mathrm{m} / \mathrm{s}$. Fig. 14 (b) shows that when the inlet flow is $30 \mathrm{~m}^{3} / \mathrm{h}$, the lowest velocity appears at the top of the spinner, with a value of $2 \mathrm{~m} / \mathrm{s}$, and the highest velocity appears at both sides of the throat, with a value of 30 $\mathrm{m} / \mathrm{s}$. Fig. 14 (c) shows that when the inlet flow is $60 \mathrm{~m}^{3} / \mathrm{h}$, the lowest velocity appears at the top of the spinner, with a value of $2 \mathrm{~m} / \mathrm{s}$, and the highest velocity appears at both sides of the throat, with a value of 54 $\mathrm{m} / \mathrm{s}$. Fig. 14 (d) shows that when the inlet flow is $90 \mathrm{~m}^{3} / \mathrm{h}$, the highest velocity appears at both sides of the throat, with a value of $78 \mathrm{~m} / \mathrm{s}$.

It can be seen that after the gas enters into the contraction section, the vortex is formed at the top of the spinner under the influence of the spinner. Under any condition of inlet flow, a lower velocity area will be formed at the top of the spinner, and the velocity at both sides of the throat is higher than that in the middle.

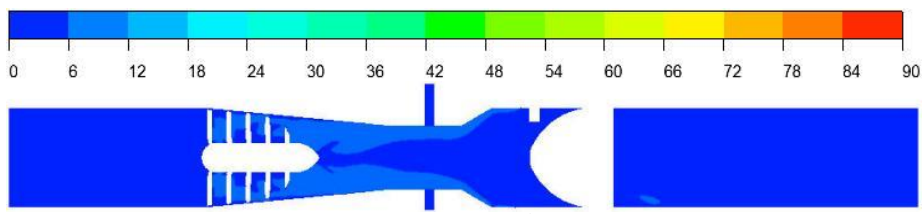

(a) $10 \mathrm{~m}^{3} / \mathrm{h}$
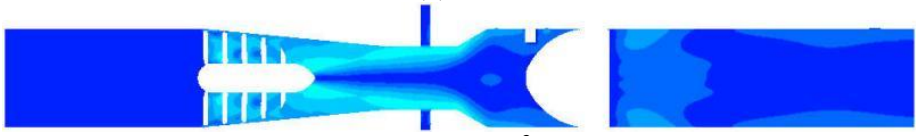

(b) $30 \mathrm{~m}^{3} / \mathrm{h}$
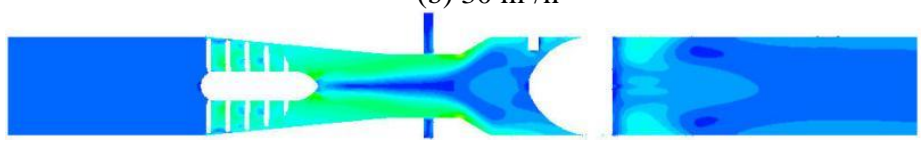

(c) $60 \mathrm{~m}^{3} / \mathrm{h}$
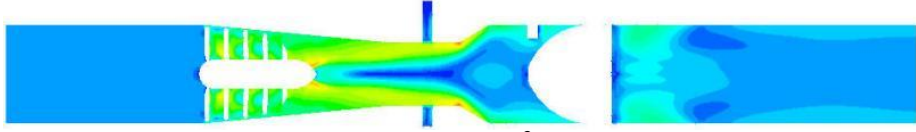

(d) $90 \mathrm{~m}^{3} / \mathrm{h}$

Fig. 14 Velocity distribution of vertical middle section $(\mathrm{m} / \mathrm{s})$

(3) Pressure sensing cross section

Fig. 15 (a) shows that when the inlet flow rate is $10 \mathrm{~m}^{3} / \mathrm{h}$, the velocity value of each part of the cross section of the vortex flowmeter has little difference, and its value is $8 \mathrm{~m} / \mathrm{s}$. Fig. 15 (b) shows that when the inlet flow rate is $30 \mathrm{~m}^{3} / \mathrm{h}$, the highest velocity appears at the wall of the flow channel, its value is $20 \mathrm{~m} / \mathrm{s}$, and the velocity at the center is low and has little change, its value is $4 \mathrm{~m} / \mathrm{s}$. Fig. 15 (c) shows that when the inlet flow rate is $60 \mathrm{~m}^{3} / \mathrm{h}$, the highest flow rate appears on the wall of the flow passage, with a value of $44 \mathrm{~m} / \mathrm{s}$. The velocity values at the center are low and have little change, with a value of $4 \mathrm{~m} / \mathrm{s}$. Fig. 15 (d) shows that when the inlet flow is $90 \mathrm{~m}^{3} / \mathrm{h}$, the highest flow velocity appears on the wall of the flow passage, with a value of $64 \mathrm{~m} / \mathrm{s}$, and the lowest flow velocity appears in the center, with a value of $4 \mathrm{~m} / \mathrm{s}$.

It can be seen that after the gas enters the throat through the spinner, the air flow is affected by the spinner and the vortex is formed at the top of the spinner, and the vortex core of the vortex moves near the center of the cross section. Under the condition of any inlet flow, the flow velocity of center of the vortex flowmeter is lower than that of the wall at the cross section, and the center of the velocity is lowest and increase gradually outward along the diameter direction. The velocity in the cross section increases with the increase of the inlet flow, the velocity near the channel wall rises significantly, and the velocity at the center changes little and remains at a low value.

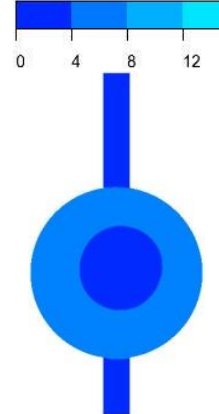

(a) $10 \mathrm{~m}^{3} / \mathrm{h}$

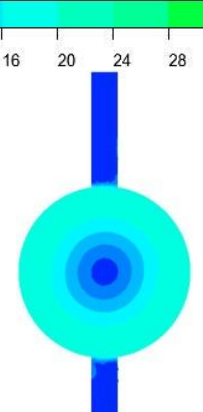

(b) $30 \mathrm{~m}^{3} / \mathrm{h}$

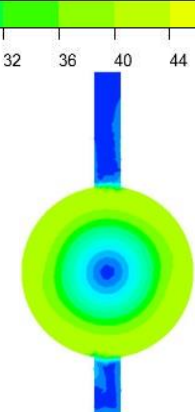

(c) $60 \mathrm{~m}^{3} / \mathrm{h}$

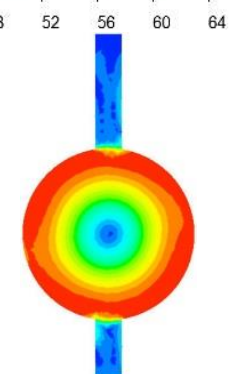

(d) $90 \mathrm{~m}^{3} / \mathrm{h}$
Fig. 15 Velocity distribution of pressure sensing cross section $(\mathrm{m} / \mathrm{s})$

\section{(4) Exit extension cross section}

Fig. 16 (a) shows that when the inlet flow rate is $10 \mathrm{~m}^{3} / \mathrm{h}$, the velocity values of each part of the cross section of the vortex flowmeter have little difference, with a value of $2 \mathrm{~m} / \mathrm{s}$. Fig. 16 (b) shows that when the inlet flow rate is $30 \mathrm{~m}^{3} / \mathrm{h}$, the highest velocity appears at the wall of the flow channel, with a value of $8 \mathrm{~m} / \mathrm{s}$, and the velocity values at the center are low and have little changed, with a value of $4 \mathrm{~m} / \mathrm{s}$, and four velocity areas around the center, with a value of $2 \mathrm{~m} / \mathrm{s}$. Fig. 16 (c) shows that when the inlet flow rate is $60 \mathrm{~m}^{3} / \mathrm{h}$, the highest flow rate appears on the wall of the flow channel, with a value of $20 \mathrm{~m} / \mathrm{s}$, and four low velocity areas appear around the center, with a value of $6 \mathrm{~m} / \mathrm{s}$. Fig. 16 (d) shows that when the inlet flow rate is $90 \mathrm{~m}^{3} / \mathrm{h}$, the highest velocity appears on the wall of the flow channel, with a value of $28 \mathrm{~m} / \mathrm{s}$, and four low velocity areas appear around the center, with a value of 8 $\mathrm{m} / \mathrm{s}$.

It can be seen from the figure that under any inlet flow condition, the velocity at the center of the vortex flowmeter outlet at the cross section is lower than that at the wall, and four low velocity areas are formed at the center and gradually increase outward along the diameter direction. The velocity in the cross section increases with the increase of the inlet flow, and the velocity in the four low velocity areas at the center changes little and remains at a low value.

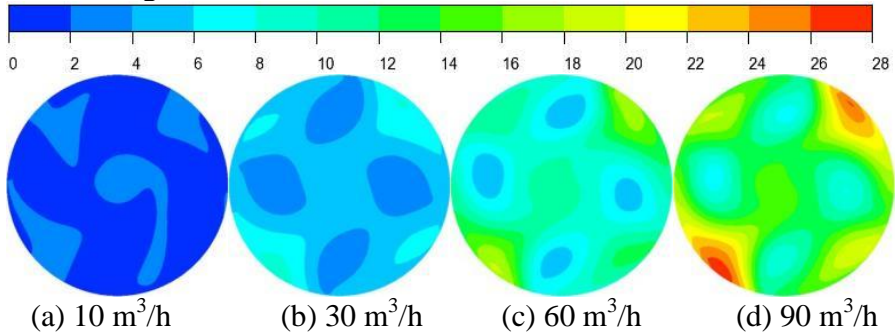

Fig. 16 Velocity distribution of exit extension cross section $(\mathrm{m} / \mathrm{s})$

(5) Top cross section of spinner

Fig. 17 (a) shows that when the inlet flow rate is $10 \mathrm{~m}^{3} / \mathrm{h}$, the velocity values of each part of the cross section of the vortex flowmeter have little difference, with a value of $14 \mathrm{~m} / \mathrm{s}$. Fig. 17 (b) shows that when the inlet flow rate is $30 \mathrm{~m}^{3} / \mathrm{h}$, the highest velocity appears at the wall of the flow channel, with a value of $20 \mathrm{~m} / \mathrm{s}$, and the velocity at the center is low and has little change, with a value of $6 \mathrm{~m} / \mathrm{s}$. Fig. 17 (c) shows that when the inlet flow rate is $60 \mathrm{~m}^{3} / \mathrm{h}$, the highest flow rate appears on the wall of the flow passage, with a value of $24 \mathrm{~m} / \mathrm{s}$, and the velocity values at the center are low and have little changed, with a value of $4 \mathrm{~m} / \mathrm{s}$. Fig. 17 (d) shows that when the inlet flow rate is 90 $\mathrm{m}^{3} / \mathrm{h}$, the highest flow rate appears on the wall of the flow passage, with 
a value of $48 \mathrm{~m} / \mathrm{s}$, and the lowest flow rate appears at the center, with a value of $4 \mathrm{~m} / \mathrm{s}$.

It can be seen that after the gas enters the throat through the spinner, the air flow is affected by the spinner and the vortex is formed at the top of the spinner, and the vortex core of the vortex moves near the center of the cross section. Under the condition of any inlet flow, the flow velocity of center of the vortex flowmeter is lower than that of the wall at the cross section, and the lowest flow velocity center is gradually increase outward along the diameter direction. The velocity in the cross section increases with the increase of the inlet flow, the velocity near the channel wall rises significantly, and the velocity at the center changes little and remains at a low value.

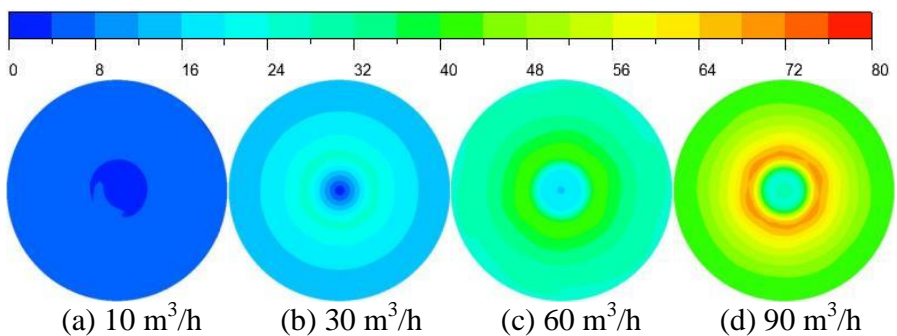

Fig. 17 Velocity distribution of cross section at the top of spinner $(\mathrm{m} / \mathrm{s})$

\subsection{Discussions}

In this paper, it is seen that the velocity contour is employed to analyze the internal flow characteristics inside vortex flowmeter. Indeed, in order to more better analyze and reveal the flow characteristics, more parameters and methods, for example velocity vector, should be employed to show and obtain more detailed flow information in future works.

\section{CONCLUSION}

In this paper, ANSYS CFX is used to calculate and simulate the flow field of vortex flowmeter. It is found that when the gas enters the contraction section, the vortex will form on the top of the vortex flowmeter due to the influence of the spinner. Under any condition of inlet flow, a lower turbulent kinetic energy area will be formed on both sides of the spinner. The turbulent kinetic energy on both sides is higher than that in the middle, and a higher turbulent kinetic energy area will be formed on both sides of the expansion section. The larger the inlet flow, the higher the value of the turbulent kinetic energy area on both sides of the expansion section. A high eddy viscosity area will be formed on both sides of the expansion section. The eddy viscosity of the two sides of the throat is lower than that of the middle part, and the higher the inlet flow is, the higher the eddy viscosity area of the two sides of the expansion section is. A lower velocity area will be formed at the top of the spinner, and the velocity on both sides of the throat is higher than that in the middle. The flow in the flow passage of the vortex flowmeter is stable, and the turbulent kinetic energy, eddy viscosity and flow velocity are evenly distributed. The value conforms to the parameters of the normal operation of the vortex flowmeter, and it can work stably when the inlet flow is large or small.

\section{ACKNOWLEDGEMENTS}

The research was financially supported by the National Natural Science Foundation of China (Grant No.51876103, No.51976202).

\section{NOMENCLATURE}

$\begin{array}{ll}\rho & \text { fluid density }\left(\mathrm{kg} / \mathrm{m}^{3}\right) \\ \mu_{t} & \text { turbulence viscous coefficient } \\ -\rho \overline{u_{i}^{\prime} u_{j}^{\prime}} & \text { average Reynolds stress }\end{array}$

\section{REFERENCES}

Arumuru, V., Dash, J.N., Dora, D., 2019, "Vortex Shedding Optical Flowmeter based on Photonic Crystal Fiber," Scientific reports, 9(1): 8313.

https://doi.org/10.1038/s41598-019-40464-2

Cui, B.L., Lv, Z.Q., Chen, D.S., 2015, "Effect of incidence angle of Spinner on performance of Precession Vortex Flowmeter," Journal of agricultural engineering, 31(02): 53-58.

https://doi: 10.3969/j.issn.1002-6819.2015.02.008

Huang S.F., Ma T.Y., Wang D., 2013, "Study on discharge coefficient of perforated orifices as a new kind of flowmeter," Exp Therm Fluid Sci, 46:74-83.

https:// doi: 10.1016/j.expthermflusci.2012.11.022

Fan J.W., Li, X.Z., Mu, D.H., 2019, “Optimization of key parameters of hydrostatic bearing based on CFX," Manufacturing technology and machine tool, (07): 37-43.

https://doi.org/10.19287/j.cnki.1005-2402.2019.07.005

He, L.H., Liu, Q., 2019, "Influence of gas composition on the measurement of Precession Vortex Flowmeter," Chemical engineering and equipment, (10): 146-147.

https://doi:CNKI:SUN:FJHG.0.2019-10-054.

Kim B.C., Pak B.C., Cho N.H., 1998, "Effects of cavitation and plate thickness on small diameter ratio orifice meters." Flow Meas Instrum, 8:85-92.

https://doi.org/10.1016/S0955-5986(97)00034-4

Tan, W.A., Cui, B.L., Zhang, Y.L., 2018, "Numerical simulation and Experimental Research on gas-solid two-phase flow of Precession Vortex Flowmeter," Mechanical engineer, (05): 37-40, 44. https://doi:CNKI:SUN:JXGU.0.2018-05-014.

Wang, X.H., 2019, "Application of Precession Vortex Flowmeter in hydrogen measurement," China well salt, 50(03): 4-5. https://doi:CNKI:SUN:ZJKY.0.2019-03-002.

Yang, Y.W., Gao, X., Li, Y., 2019, "Application analysis of intelligent Precession Vortex Flowmeter in oil field energy conservation," Petroleum and petrochemical energy conservation, 9(06): 33-35, 37, 9. https://doi:CNKI:SUN:GWYT.0.2019-06-014.

Zheng, Y., Yao, P.X., 2019, "Flow field analysis of new type synchronous valve based on CFX," Hydraulic and pneumatic, (03): 126-131.

https://doi.org/10.11832/j.issn.1000-4858.2019.03.021

Zhang, C.L., Cui, B.L., Zhang, Y.L., et al., 2019, "Experimental and numerical study on swirlmeter with different helix angles of swirler," Transactions of the Institute of Measurement and Control, 41(11): 3103-3120.

https:// doi.org/10.1177/0142331218823859

Zhang, Y., 2017, "Uncertainty evaluation of indication error measurement of Precession Vortex Flowmeter," Measurement and test technology, 44(11): 102, 104. https://doi:10.15988/j.cnki.1004-6941.2017.11.045.

Zhou, Y., 2019, "Exploration on the application value of flow measurement in the field of energy measurement," Instrument standardization and measurement, (02): 42-43, 48. https://doi:CNKI:SUN:YQBJ.0.2019-02-029. 